\title{
Sports participation and health-related quality of life: a longitudinal observational study in children
}

\author{
Janet Moeijes $^{1,2}$ (D) . Jooske T. van Busschbach ${ }^{1,3} \cdot$ Ruud J. Bosscher $^{1} \cdot$ Jos W. R. Twisk ${ }^{2}$
}

Accepted: 27 May 2019 / Published online: 3 June 2019

(c) The Author(s) 2019

\begin{abstract}
Purpose In this study, longitudinal associations between sports participation and health-related quality of life (HRQoL) were explored. Sports participation was operationalized as membership of a sports club, frequency of sports participation, performing individual versus team sports and performing indoor versus outdoor sports. The concept of HRQoL referred to the self-perceived enjoyment and satisfaction with one's personal health situation.

Methods Data from 618 fourth-grade primary school children were included at baseline; 10-13 months later, 417 children (response rate 67.5\%) were retained. At both time points, children reported on sports participation (Move and Sports Monitor Questionnaire-youth aged 8-12 years) and health-related quality of life (KIDSCREEN-52). Because of the clustering of children in schools, data were analysed using linear mixed models. Analyses were adjusted for sex, age, BMI, household composition, SES and frequency of sports participation.

Results The questionnaires were fully completed by 417 children. High sports-active children showed better scores on almost all dimensions of HRQoL than moderate [difference $(B)=-1.82(p=0.05)$ to $-1.51(p=0.05)$ ] or low ports-active children [difference $(B)=-3.67(p<0.001)$ to $-1.95(p=0.03)$ ] and non-sports club members [difference $(B)=-5.58(p<0.001)$ to $-2.65(p=0.02)]$. Unlike frequency, the other examined characteristics of sports participation were only to a limited extent longitudinal associated with HRQoL.

Conclusion As frequency is more relevant than the form of sports participation, children should be encouraged to perform any kind of sports activity on a very regular base.
\end{abstract}

Keywords Children · Frequency of sports participation · Outdoor sports · Team sports · Health-related quality of life . Longitudinal associations

\section{Introduction}

Health-related quality of life (HRQoL) is an essential outcome measure for the evaluation of health care programs and services $[1,2]$. This multidimensional construct covers "physical, emotional, mental, social, and behavioural components of well-being and functioning as perceived by patients and/or other individuals" [3]. Whereas psychosocial health relates to a person's actual health situation, the

Electronic supplementary material The online version of this article (https://doi.org/10.1007/s11136-019-02219-4) contains supplementary material, which is available to authorized users.

Janet Moeijes

j.moeijes@windesheim.nl

Extended author information available on the last page of the article concept of HRQoL pertains to his or her self-perceived well-being and functioning [4].

Recent systematic reviews suggest that HRQoL is positively associated with sports participation. With one review focussing on adults [5], three other recent reviews present an overview of research on children (aged twelve and younger, in primary education) and adolescents (thirteen and older, in high school). Eime et al. [6] indicated that sports participation, especially performing club-based sports, may lead to better HRQoL in the broad age group of children and adolescents. They found a stronger association for participation in team sports compared to participation in individual sports. Wu et al. [7] concluded from their systematic review that children and adolescents with a higher frequency of physical activity show better HRQoL. The systematic review and meta-analysis by Marker et al. [8] identified the same but relatively weak 
relationship between physical activity and better HRQoL in children and adolescents.

In a majority of studies included in recent reviews on children and adolescents, physical activity as such is emphasized, ignoring whether or not children and adolescents were active members of a sports club or had a more active life-style in general. Contrary to the studies reviewed by Eime et al. [6], all studies reviewed by Marker et al. [8] and the majority of studies reviewed by Wu et al. [7] did not reflect on sports participation as a separate variable in their analyses.

Of those studies aimed at sports participation, most focused on samples of adolescents, for instance high school populations [9-16] and only few studied sports participation in children in the age of twelve and younger [17-21]. Moreover, although some of the reviewed studies on children use the concept of emotional or social wellbeing $[17,18]$, the health aspects investigated in these studies relate more to a child's actual health situation than to his or her evaluation of this state. So, these studies paid more attention to the psychosocial health of children than to their HRQoL.

All in all, there are three studies that aimed to study the relationship between sports participation and HRQoL in children of twelve and younger [19-21]. Two of these three studies, Sánchez-López et al. [19] and Tsiros et al. [20] limit their scope to membership of a sports club and/ or frequency of sports participation. In their conclusion, Tsiros et al. [20] did recommend to pay attention to a potential relationship between performing indoor versus outdoor sports and HRQoL. Only Vella et al. [21] took the distinction between team and individual sports into account among various other characteristics of sports participation. Their study confirmed that not only membership of a sports club but also more specifically performing team sports instead of individual sports were associated with better HRQoL.

In line with Coalter [22] and Marker et al. [8] who stated that progress in this field can be made by focussing future research on specific characteristics of sports participation, the present study explored longitudinal associations between various characteristics of sports participation and different dimensions of HRQoL. It concerned associations between membership of a sports club, frequency of sports participation, performing individual versus team sports and performing indoor versus outdoor sports on the one hand and ten dimensions of HRQoL on the other.

As noted by Marker et al. [8], most descriptive studies on the relationship between sports participation and HRQoL have a cross-sectional design. The present study is, however, aimed at exploring longitudinal associations.

\section{Methods}

\section{Study design and participants}

This national-representative study examined sports participation and HRQoL in fourth- and fifth-grade primary school children in the Netherlands. The study comprised a cross-sectional component to be published separately, and a longitudinal component with data gathering repeated after a period of 10-13 months reported here. Data were collected from November 2011 to June 2014, mostly in autumn and spring.

The primary schools used in the present study were spread fairly well in terms of geographical location (eight of the 12 provinces) and urbanization rate (14 schools in rural areas and 15 schools in urban areas). As a result, the group of children included in the longitudinal part of the study was comparable with the general Dutch population of primary school children for neighbourhood socioeconomic status (SES), i.e. $6.4 \%$ of the children in the sample had a low SES background, while $5.5 \%$ of all Dutch children lived in low SES families [23]. Body mass index (BMI), i.e. BMI by underweight and BMI by overweight were respectively 6.4 and $13.1 \%$ in the sample versus 6.6 and $11.6 \%$ in the population [24] and for sports participation (in terms of membership in a sports club) with $87 \%$ in the sample versus $83 \%$ in the general population [25].

The choice to test children in the fourth and then a year later in the fifth grade was based on the fact that children of 10-12 are old enough to independently complete questionnaires. This is a requisite for adequate self-report on HRQoL that significantly differs from reporting by parents or guardians [26]. Furthermore, these children were young enough not to have entered puberty in which physical and psychological changes $[27,28]$ may overshadow possible associations between sports participation and HRQoL.

Primary schools were first addressed by phone and email. If a school director replied to be interested in the research, an email with detailed information was sent, and he or she was again contacted by phone 1 week later. After the school director had given permission by phone for research activities at this school, he or she supplied written information about the aim, nature and practice of the research to the parents and eventual guardians of children. Written informed consent from parent or guardian was a prerequisite to participate in this research.

Of the 73 schools involved in the cross-sectional part the study, 29 schools also participated in the longitudinal part. Most of these schools (21) were involved twice in the longitudinal part of the study. Some schools (eight) participated three times (for more information see Supplementary 
material-Additional file 1: Flowchart gathering schools). Headmasters gave permission for each occasion.

At the initial meeting, children were given a booklet containing questionnaires which were piloted in a small test sample of 43 children in three primary schools. The questionnaires had to be completed individually in the classroom, whereby children could consult their classroom teacher if assistance was needed. The questionnaires were collected 1 week later. Subsequently, anthropometric data were obtained during school time.

Figure 1 presents information about the sample recruitment and selection for this longitudinal study.

The study was conducted in accordance with the guidelines proposed by the World Medical Association Declaration of Helsinki and was approved by the Medical Ethical Committee at VU University Medical Center Amsterdam (12/151). All parents and guardians of children in the sample provided a written informed consent.

\section{Measures}

\section{HRQOL}

HRQoL was measured using the KIDSCREEN-52, a selfreported generic measure of HRQoL in children and adolescents aged between 8 and 18 years [3,29]. We used a Dutch version of the original English version of the questionnaire. The Dutch version was obtained by translating the original version according to a standardized methodology based on international cross-cultural translation guidelines [30, 31].

The KIDSCREEN-52 includes 52 items covering ten dimensions which are classified into three domains. The 'physical well-being' dimension relates to the physical domain and includes five items, e.g. the item 'In general, how would you say your health is?'. The psychological domain comprises the dimensions 'psychological wellbeing' (six items, e.g. 'Thinking about the last week...Has your life been enjoyable?), 'moods and emotions' (seven items, e.g. 'Thinking about the last week...Have you felt sad?'), and 'self-perception' dimension (five items, e.g. 'Thinking about the last week ... Have you been happy with the way you are?'). The social domain relates to the dimensions 'autonomy' (5 items, e.g. 'Thinking about the last week...Have you had enough time for yourself?'), 'parent relations and home life' (six items, e.g. 'Thinking about the last week...Have your felt loved by your parent(s)?'), 'social support and peers' (six items, e.g. 'Thinking about the last week...Have you had fun with your friends?'), 'school environment' (six items, e.g. 'Thinking about the last week ... Have you been happy at school?'), 'social acceptance (bullying)' (three items', e.g. Thinking about the last week Have other girls and boys bullied you?'), and 'financial resources' (three items, e.g. 'Thinking about the last week...Have you had enough money for your expenses?').

All items are rated on a five-point Likert scale (ranging from "never" to "always" or from "not at all" to " "extremely"). After recoding some of the items, a higher score indicates better HRQoL.

The KIDSCREEN-52 has a satisfactory internal consistency with Cronbach's alphas for the ten dimensions ranging from 0.77 to $0.89[3,32]$. The test-retest reliability is also satisfying with intraclass correlation coefficients (ICCs) ranging from 0.56 to 0.77 [3, 32]. The questionnaire shows good results in terms of convergent, known groups' and criterion validity [32].

\section{Sports participation}

The study focused on sports activities in sports clubs, the primary environment in which Dutch children participate in sports [33]. A child's participation in sports club activities was measured using two items from the self-report Move and Sports Monitor Questionnaire (MSMQ) - youth aged 8-12 years [34]: membership in a sports club and frequency of training and matches per week. Frequency of sports participation was classified into tertiles. We added a third question about the sport(s) in which a child participated, which made it possible to determine whether the child practised individual and/or team sports and whether he or she was involved in indoor and/or outdoor sports. As described in Moeijes et al. [35], the validation of the questions about sports participation took place in a pilot study among primary school children, an expert meeting, individual expert consultations and a comparison of some research findings about children's sports participation with national data. See for more information Supplementary material-Additional file 2: Validation process sports participation questions.

\section{Potential confounders}

The covariates of age (continuous), sex (dichotomous), BMI (continuous), household composition (dichotomous) and SES (continuous) were used in all analyses. According to literature, these factors are associated with HRQoL [1, 36-38]. Frequency of sports participation (continuous) was used as a covariate in the analyses of the associations between performing individual versus team sports and indoor versus outdoor sports on the one hand and HRQoL on the other. These associations were analysed given a certain frequency of sports participation to avoid the risk of finding spurious associations or overlooking important associations.

Parents or guardians reported the child's date of birth and sex. Researchers who visited the schools measured height and weight. Height was measured by the Seca 201 or 203 


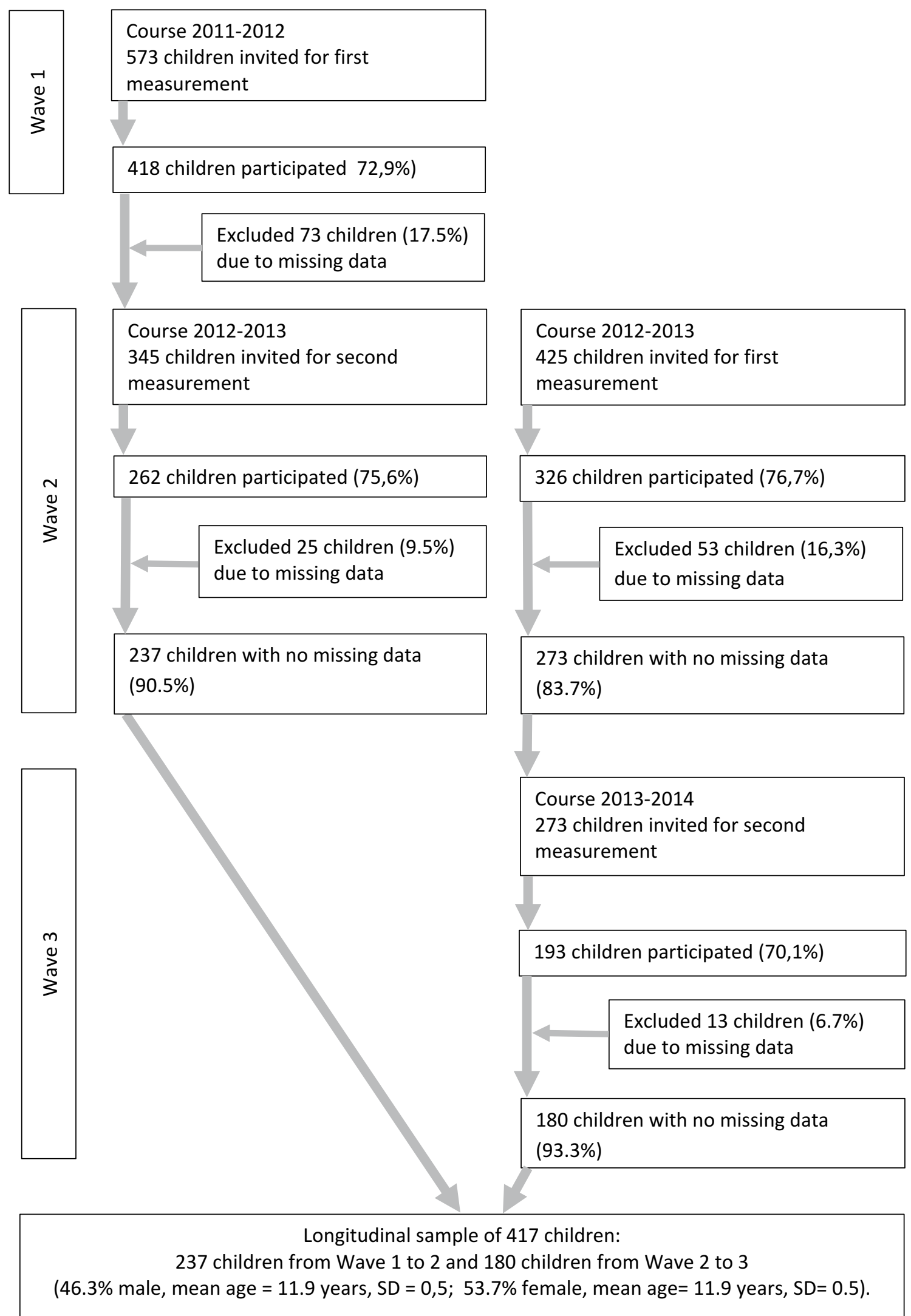

Fig. 1 Flowchart regarding the gathering of children 
system (Basel, Switzerland) and weight by the Seca Sensa 804 (Basel, Switzerland) or the Tanita BC 601 digital scale (Tokyo, Japan). BMI was calculated as weight divided by height squared $\left(\mathrm{kg} / \mathrm{m}^{2}\right)$ [39]. Household composition was measured as living in a two-parent family or another type of household, for example a one-parent family [40]. The SES of the child's parents or guardians was based on postcodes and the status score per postcode derived from the Dutch Social and Cultural Planning Office in 2010 [41].

\section{Statistical analyses}

As prescribed in the KIDSCREEN manual, Rasch scores were calculated for each dimension of HRQoL. These scores were transformed into $T$-values with a mean of 50 and a standard deviation (SD) of 10 [3].

Children who had missing KIDSCREEN-52 data were excluded to conform to the procedure outlined in the manual. The scores on the 5-7-items dimensions were only calculated if not more than one item of the dimension was left unanswered. The scores on the three-items dimension were only calculated if all questions were answered. A greater number of missing data resulted in the exclusion of the child from the analyses [3]. Children who failed to answer one or more questions concerning the sports participation questionnaire MSMQ, BMI, SES or household composition, were excluded from the analyses.

Data for the children who did not participate in the second measurement were compared with the data for the children who participated in both measurements using independent $t$ tests (for continuous variables) or $\chi^{2}$ tests (for dichotomous and categorical variables).

The longitudinal associations between each of the characteristics of sports participation and each of the ten outcome variables separately were analysed using linear mixed models, taking into account the three-level structure of the data: repeated measures (level 1) were clustered within children (level 2) and children were clustered within the schools (level 3). For the outcome variables (i.e. the ten dimensions of the KIDSCREEN-52), multilevel models included random intercepts for the children and the schools. Before analyses, the normality of the distribution of the outcome variables was determined by visual examination of histograms.

In addition to crude analyses, analyses were performed adjusting for sex, age, BMI, household composition, SES and frequency of sports participation. Frequency of sports participation as a potential confounder co-varied moderately with performing individual versus team sports $(\rho=0.59, p<0.001)$ and performing indoor versus outdoor sports $(\rho=0.63, p<0.001)$. The other potential confounders co-varied with characteristics of sports participation only slightly. Thus, there is no multicollinearity among the covariates and the independent variables.

All data were analysed using IBM SPSS (version 24, IBM, New York, USA). For all analyses, a two-tailed significance level of $p<0.05$ was considered statistically significant.

\section{Results}

A number of 618 fourth-grade primary school children filled in the questionnaires in the first measurement. The majority of these children (417, response rate $67.5 \%$ ) fully completed the questionnaires in the second measurement and were included in the study. The 201 excluded fifth-graders $(32.5 \%)$ did not participate in the second measurement because they were no longer interested (163 children), or were excluded due to missing data (38 children of whom 1 , 3 and 34 had missing data on sports participation characteristics, BMI and HRQoL, respectively).

The group of children who only supplied information for the first measurement differed significantly from the group of children who were measured twice. Those who dropped out of the study were more active (frequency of sports participation: 2.73 vs. $2.45 ; p=0.05)$ and had lower scores on physical well-being (54.71 vs. 56.72 points, $p=0.01$ ) than those who remained in the study. No other significant differences were found. Table 1 shows descriptive information of the sample under study.

\section{Membership sports club}

According to the analyses adjusted for gender, age, BMI, SES and household composition, membership of a sports club was significantly longitudinally associated with better HRQoL in the physical domain (dimension 'physical wellbeing', $B=3.02, p=0.002$ ), to a lesser extent in the social domain (dimension 'social support and peers', $B=2.10$, $p=0.03$; 'financial resources', $B=2.15, p=0.02$ ), and not at all in the psychological domain (Table 2).

\section{Frequency of sports participation}

The analyses adjusted for the five before-mentioned covariates show that high and moderate sports-active children significantly had better HRQoL than low sports-active children and non-sports club members in the physical domain (dimension 'physical well-being', $B=-3.67, p<0,001$ and $B=-1.94, p=0.02$, respectively, for low sports-actives; $B=-5.58, p<0.001$ and $B=-3.81, p<0.001$, respectively, for non-sports club members).

For the psychological domain, high and moderate sports-active children showed better HRQoL than low 
Table 1 Demographic characteristics of the sample at baseline $(N=618)$ and follow-up $(N=417)$

\begin{tabular}{|c|c|c|c|c|c|c|c|c|}
\hline & \multicolumn{4}{|c|}{ Fourth grade } & \multicolumn{4}{|c|}{ Fifth grade } \\
\hline & $N$ & $\%$ & Mean & SD & $N$ & $\%$ & Mean & SD \\
\hline \multicolumn{9}{|l|}{ Sex } \\
\hline Boys & 288 & 46.6 & & & 193 & 46.3 & & \\
\hline Girls & 330 & 53.4 & & & 224 & 53.7 & & \\
\hline Age & & & 11.0 & 0.5 & & & 11.9 & 0.5 \\
\hline BMI & & & 17.7 & 2.4 & & & 18.2 & 2.3 \\
\hline SES & & & 0.25 & 0.92 & & & 0.29 & 0.89 \\
\hline \multicolumn{9}{|l|}{ Household composition } \\
\hline Two parent family & 503 & 81.4 & & & 328 & 78.7 & & \\
\hline Others & 115 & 18.6 & & & 89 & 21.3 & & \\
\hline \multicolumn{9}{|l|}{ Membership sports club } \\
\hline No & 76 & 12.3 & & & 56 & 13.4 & & \\
\hline Yes & 542 & 87.7 & & & 361 & 86.6 & & \\
\hline Frequency of sports participation & & & 2.48 & 1.65 & & & 2.56 & 1.56 \\
\hline Non-members & 76 & 12.3 & & & 56 & 13.4 & & \\
\hline Low sports-actives ${ }^{\mathrm{a}}$ & 210 & 34.0 & & & 117 & 28.1 & & \\
\hline Moderate sports-actives $^{\mathrm{b}}$ & 171 & 27.7 & & & 145 & 34.8 & & \\
\hline High sports-actives $^{c}$ & 161 & 26.1 & & & 99 & 23.7 & & \\
\hline \multicolumn{9}{|l|}{ Individual versus team sports } \\
\hline Non-members & 76 & 12.3 & & & 56 & 13.4 & & \\
\hline Individual sports & 143 & 23.1 & & & 93 & 22.3 & & \\
\hline Team sports & 297 & 48.1 & & & 210 & 50.4 & & \\
\hline Individual as well as team sports & 102 & 16.5 & & & 58 & 13.9 & & \\
\hline \multicolumn{9}{|l|}{ Indoor versus outdoor sports } \\
\hline Non-members & 76 & 12.3 & & & 56 & 13.4 & & \\
\hline Indoor sports & 186 & 30.1 & & & 114 & 27.3 & & \\
\hline Outdoor sports & 277 & 44.8 & & & 208 & 49.9 & & \\
\hline Indoor as well as outdoor sports & 79 & 12.8 & & & 39 & 9.4 & & \\
\hline \multicolumn{9}{|l|}{ Kidscreen-52 } \\
\hline $\begin{array}{l}\text { Physical domain } \\
\text { Physical well-being }\end{array}$ & & & 56.07 & 9.37 & & & 56.83 & 9.93 \\
\hline $\begin{array}{l}\text { Psychological domain } \\
\text { Psychological well-being }\end{array}$ & & & 54.84 & 8.65 & & & 56.48 & $9.23^{\mathrm{d}}$ \\
\hline Moods and emotions & & & 51.50 & 10.16 & & & 54.41 & $10.71^{\mathrm{d}}$ \\
\hline Self-perception & & & 55.23 & 9.28 & & & 56.18 & 9.92 \\
\hline $\begin{array}{l}\text { Social domain } \\
\text { autonomy }\end{array}$ & & & 54.48 & 8.62 & & & 56.28 & $9.10^{\mathrm{d}}$ \\
\hline Parent relation and home life & & & 56.08 & 8.41 & & & 57.14 & $8.77^{\mathrm{d}}$ \\
\hline Social support and peers & & & 53.53 & 9.16 & & & 56.12 & $9.42^{\mathrm{d}}$ \\
\hline School environment & & & 56.74 & 8.94 & & & 57.74 & 8.95 \\
\hline Social acceptance (bullying) & & & 49.09 & 10.43 & & & 50.43 & $9.92^{\mathrm{d}}$ \\
\hline Financial resources & & & 53.33 & 9.27 & & & 55.57 & $8.52^{\mathrm{d}}$ \\
\hline
\end{tabular}

${ }^{\text {a }}$ Low sports-actives: 1-2.2 times a week

b Moderate sports-actives: 2.25-3 times a week

${ }^{c}$ High sports-actives: 3.02-9 times a week

${ }^{\mathrm{d}}$ Scores 1 st and 2 nd measurement significantly differ 
Table 2 Associations between membership of a sports club and HRQOL dimensions

\begin{tabular}{|c|c|c|c|c|c|c|}
\hline & \multicolumn{3}{|l|}{ Crude analyses } & \multicolumn{3}{|c|}{ Adjusted analyses $^{\mathrm{a}}$} \\
\hline & $B^{\mathrm{b}}$ & $p$ & $\mathrm{CI}$ & $\overline{B^{\mathrm{b}}}$ & $p$ & $\mathrm{CI}$ \\
\hline \multicolumn{7}{|l|}{ Physical domain } \\
\hline \multicolumn{7}{|c|}{ Physical well-being } \\
\hline Non-member & Reference group & & & & & \\
\hline Member & 3.72 & $<0.001$ & $1.77-5.67$ & 3.20 & 0.002 & $1.25-5.14$ \\
\hline \multicolumn{7}{|c|}{ Psychological domain } \\
\hline \multicolumn{7}{|c|}{ Psychological well-being } \\
\hline Non-member & Reference group & & & & & \\
\hline Member & 0.58 & 0.53 & -1.23 to 2.40 & 0.47 & 0.62 & -1.36 to 2.29 \\
\hline \multicolumn{7}{|c|}{ Moods and emotions } \\
\hline Non-member & Reference group & & & & & \\
\hline Member & -0.30 & 0.78 & -2.43 to 1.82 & -0.36 & 0.74 & -2.48 to 1.77 \\
\hline \multicolumn{7}{|l|}{ Self-perception } \\
\hline Non-member & Reference group & & & & & \\
\hline Member & 0.47 & 0.64 & -1.49 to 2.43 & -0.02 & 0.98 & -1.96 to 1.91 \\
\hline \multicolumn{7}{|l|}{ Social domain } \\
\hline \multicolumn{7}{|l|}{ Autonomy } \\
\hline Non-member & Reference group & & & & & \\
\hline Member & 0.48 & 0.61 & -1.35 to 2.30 & 0.37 & 0.69 & -1.45 to 2.20 \\
\hline \multicolumn{7}{|c|}{ Parents and home life } \\
\hline Non-member & Reference group & & & & & \\
\hline Member & 1.27 & 0.15 & -0.47 to 3.02 & 1.16 & 0.19 & -0.59 to 2.90 \\
\hline \multicolumn{7}{|c|}{ Social support and peers } \\
\hline Non-member & Reference group & & & & & \\
\hline Member & 2.18 & $\mathbf{0 . 0 3}$ & $0.24-4.12$ & 2.10 & $\mathbf{0 . 0 3}$ & 0.15 to 3.01 \\
\hline \multicolumn{7}{|c|}{ Social acceptance (bullying) } \\
\hline Non-member & Reference group & & & & & \\
\hline Member & 1.27 & 0.24 & -0.83 to 3.38 & 1.13 & 0.30 & -0.99 to 3.26 \\
\hline \multicolumn{7}{|c|}{ School environment } \\
\hline Non-member & Reference group & & & & & \\
\hline Member & -0.14 & 0.88 & -1.94 to 1.66 & -0.04 & 0.97 & -1.86 to 1.78 \\
\hline \multicolumn{7}{|c|}{ Financial resources } \\
\hline Non-member & Reference group & & & & & \\
\hline Member & 2.29 & 0.01 & $0.47-4.11$ & 2.15 & 0.02 & $0.32-3.97$ \\
\hline
\end{tabular}

Significant p's are in bold

${ }^{a}$ Adjusted for gender, age, BMI, SES, and household composition

${ }^{\mathrm{b}}$ Unstandardized regression coefficient sports-active children for the dimension 'psychological well-being' $(B=-3.53, p<0.001$ and $B=-2.07, p=0.01$, respectively). Furthermore, high sports-active children showed better HRQoL than non-sports club members for the dimension 'psychological well-being' $(B=-2.65, p=0.02)$ and showed better HRQoL than moderate and low sportsactives for the dimension 'moods and emotions' $(B=-1.82$, $p=0.05$ and $B=-2.36, p=0.02$, respectively). For the dimension 'self-perception', high sports-active children showed better HRQoL than low sports-active children $(B=-1.95, p=0.03)$.

In the social domain, high sports-active children showed better HRQoL than moderate and low sports-active children and non-sports club members for the dimension 'parents and homelife' $(B=-1.51, p=0.05, B=-2.54, p=0.002$ and $B=-2.90, p=0.01$, respectively). Finally, for the dimension 'social support and peers', high sports-active children showed better HRQoL than low sports-active children 
and non-sports club members $(B=-2.97, p=0.001$ and $B=-4.00, p<0.001$, respectively) (Table 3 ).

\section{Performing individual versus team sports}

According to the analyses adjusted for the five abovementioned covariates and frequency of sports participations, children participating in team sports showed significantly worse HRQoL on the dimension 'moods and emotions' compared to children participating in individual sports $(B=-2.22, p=0.03)$. No other significant associations were observed (Table 4).

\section{Performing indoor versus outdoor sports}

The analyses adjusted for frequency of sports participation, and the other five covariates show that children performing outdoor sports had a significantly more favourable HRQoL in the psychological domain (dimension 'self-perception'; $B=1.82, p=0.05$ ) and the social domain (dimension 'financial resources'; $B=2.36, p=0.01$ ) compared to children performing indoor sports. Children performing indoor sports as well as outdoor sports showed also a better HRQoL in for the dimension 'self-perception' $(B=3.26, p=0.01)$ than children performing indoor sports. There was no significant difference observed for the physical domain (Table 5).

The results presented in Table 5 indicate that frequency of sports participation (added to the models as a continuous variable) was a strong confounder in most of the associations between performing indoor versus outdoor sports and HRQoL.

\section{Discussion}

The present study aimed to explore longitudinal associations between characteristics of sports participation and HRQoL. Of all examined characteristics of sports participation, frequency is by far the most important characteristic that is longitudinally associated with more favourable HRQoL. Membership of a sports club and performing outdoor sports also showed, albeit to a limited extent, longitudinal associations with better HRQoL.

\section{Membership of a sports club}

The observed associations between being a member of a sports club and a more favourable HRQoL for some dimensions are in line with those of previous studies for adults [42, 43], adolescents [11, 44, 45] and children
[19-21]. With regard to the physical domain of HRQoL the explanation for the association with the dimension 'physical well-being' could be that engaging in sports activities fosters a child's physical condition [46, 47], which results in higher physical well-being [48, 49]. With respect to the social domain, the longitudinal association of membership of a sports club with better HRQoL for the dimension 'social support and peers' does suggest that organized sports activities provide possibilities for children to interact with friends and peers [50]. These interactions facilitate positive social experiences and better social skills leading to a more favourable HRQoL [36, 51].

That only a limited number of associations were found could be explained by the large proportion of children in our sample who were low or moderate sports-active. In this study, it were especially the high sports-active children that showed better HRQoL on almost all dimensions than their peers.

\section{Frequency of sports participation}

Compared to the other examined characteristics of sports participation, higher frequency is by far most longitudinally associated with better HRQoL in this study. With respect to the physical domain, it is likely that sports participation has a 'feel-good' effect [52] and affective response [53,54], which are expressed in, amongst others, a better subjective vitality [55]. In this context, subjective vitality refers to feeling alive and energetic after sports participation and occurs after sports participation during at least 3 days a week [56]. However, an alternative explanation for the longitudinal association between higher frequency and better HRQoL in the physical domain would be that those students who had better HRQoL were more likely to participate in sports activities.

Regarding the psychological domain, based on the Selfdetermination Theory [57], an explanation for the longitudinal association of frequency of sports participation with better HRQoL for all three dimensions at stake might be that high sports-active children fulfil basic psychological needs for autonomy, competence and relatedness by spending several days at a sports club. Furthermore, high or moderate sports-active children have the possibility to develop better motor skills, which in turn contributes to a positive sports self-perception [58-60]. Finally, the 'feel-good' effect of high or moderate active sports participation gives, besides benefits in the physical domain, also a pleasant mood and joy in the psychological domain [56].

With respect to the social domain, the observed longitudinal associations with the dimension 'home life and parents' and 'social support and peers' suggest that in high sportsactive children there is probably a transfer of the various 
Table 3 Associations between frequency of sports participation and HRQOL dimensions

\begin{tabular}{|c|c|c|c|c|c|c|}
\hline & \multicolumn{3}{|l|}{ Crude analyses } & \multicolumn{3}{|c|}{ Adjusted analyses $^{\mathrm{a}}$} \\
\hline & $\mathrm{B}^{\mathrm{b}}$ & $\mathrm{p}$ & CI & $\mathrm{B}^{\mathrm{b}}$ & $\mathrm{p}$ & CI \\
\hline \multicolumn{7}{|l|}{ Physical domain } \\
\hline \multicolumn{7}{|l|}{ Physical well-being } \\
\hline High sports-active & Reference group & & & & & \\
\hline Moderate sports-active & -1.55 & 0.07 & -3.23 to 0.13 & -1.74 & 0.04 & -3.41 to -0.06 \\
\hline Low sports-active & -3.98 & $<0.001$ & -5.75 to -2.20 & -3.67 & $<0.001$ & -5.46 to -1.89 \\
\hline Non-members & -6.16 & $<0.001$ & -8.44 to -3.89 & -5.58 & $<0.001$ & -7.86 to -3.30 \\
\hline \multicolumn{7}{|l|}{ Psychological domain } \\
\hline \multicolumn{7}{|l|}{ Psychological well-being } \\
\hline High sports-active & Reference group & & & & & \\
\hline Moderate sports-active & -1.25 & 0.12 & -2.82 to 0.31 & -1.44 & 0.07 & -3.00 to 0.13 \\
\hline Low sports-active & -3.61 & $<0.001$ & -5.25 to -1.97 & -3.53 & $<0.001$ & -5.18 to -1.87 \\
\hline Non-members & -2.66 & 0.01 & -4.78 to -0.53 & -2.65 & 0.02 & -4.79 to -0.51 \\
\hline \multicolumn{7}{|l|}{ Moods and emotions } \\
\hline High sports-active & Reference group & & & & & \\
\hline Moderate sports-active & -1.51 & 0.11 & -3.34 to 0.33 & -1.82 & 0.05 & -3.64 to 0.00 \\
\hline Low sports-active & -2.72 & 0.01 & -4.66 to -0.78 & -2.36 & 0.02 & -4.31 to -0.41 \\
\hline Non-members & -1.51 & 0.24 & -4.03 to 1.01 & -1.42 & 0.27 & -3.95 to 1.10 \\
\hline \multicolumn{7}{|l|}{ Self-perception } \\
\hline High sports-active & Reference group & & & & & \\
\hline Moderate sports-active & -0.64 & 0.46 & -2.34 to 1.06 & -1.03 & 0.23 & -2.71 to 0.64 \\
\hline Low sports-active & -2.42 & 0.01 & -4.21 to -0.63 & -1.95 & 0.03 & -3.73 to -0.17 \\
\hline Non-members & -1.85 & 0.12 & -4.16 to 0.47 & -1.25 & 0.28 & -3.54 to 1.03 \\
\hline \multicolumn{7}{|l|}{ Social domain } \\
\hline \multicolumn{7}{|l|}{ Autonomy } \\
\hline High sports-active & Reference group & & & & & \\
\hline Moderate sports-active & -0.50 & 0.55 & -2.09 to 1.11 & -0.74 & 0.36 & -2.34 to 0.85 \\
\hline Low sports-active & -1.52 & 0.8 & -3.20 to 0.16 & -1.26 & 0.15 & -2.95 to 0.43 \\
\hline Non-members & -1.33 & 0.23 & -3.48 to 0.82 & -1.21 & 0.27 & -3.37 to 0.95 \\
\hline \multicolumn{7}{|l|}{ Parents and home life } \\
\hline High sports-active & Reference group & & & & & \\
\hline Moderate sports-active & -1.30 & 0.09 & -2.81 to 0.20 & -1.51 & 0.05 & -3.01 to -0.01 \\
\hline Low sports-active & -2.64 & 0.001 & -4.23 to -1.06 & -2.54 & 0.002 & -4.13 to -0.94 \\
\hline Non-members & -2.95 & 0.01 & -5.01 to -0.89 & -2.90 & 0.01 & -4.97 to -084 \\
\hline \multicolumn{7}{|l|}{ Social support and peers } \\
\hline High sports-active & Reference group & & & & & \\
\hline Moderate sports-active & -1.36 & 0.12 & -3.05 to 0.34 & -1.53 & 0.08 & -3.22 to 0.15 \\
\hline Low sports-active & -2.91 & 0.001 & -4.69 to -1.14 & -2.97 & 0.001 & -4.75 to -1.18 \\
\hline Non-members & -3.91 & 0.001 & -6.19 to -1.63 & -4.00 & 0.001 & -6.29 to -1.71 \\
\hline \multicolumn{7}{|l|}{ Social acceptance (bullying) } \\
\hline High sports-active & Reference group & & & & & \\
\hline Moderate sports-active & -0.05 & 0.96 & -1.88 to 1.79 & -0.16 & 0.86 & -2.00 to 1.67 \\
\hline Low sports-active & -1.95 & 0.05 & -3.88 to -0.03 & -1.85 & 0.06 & -3.80 to 0.10 \\
\hline Non-members & -2.17 & 0.09 & -4.66 to 0.31 & -2.08 & 0.11 & -4.60 to 0.44 \\
\hline \multicolumn{7}{|l|}{ School environment } \\
\hline High sports-active & Reference group & & & & & \\
\hline Moderate sports-active & -0.25 & 0.76 & -1.82 to 1.33 & -0.17 & 0.83 & -1.75 to 1.41 \\
\hline Low sports-active & -1.23 & 0.15 & -2.89 to 0.43 & -1.49 & 0.08 & -3.17 to 0.20 \\
\hline Non-members & -0.50 & 0.65 & -2.63 to 1.64 & -0.72 & 0.51 & -2.87 to 1.44 \\
\hline
\end{tabular}


Table 3 (continued)

\begin{tabular}{|c|c|c|c|c|c|c|}
\hline & \multicolumn{3}{|l|}{ Crude analyses } & \multicolumn{3}{|c|}{ Adjusted analyses $^{\mathrm{a}}$} \\
\hline & $\mathrm{B}^{\mathrm{b}}$ & $\mathrm{p}$ & CI & $\mathrm{B}^{\mathrm{b}}$ & $\mathrm{p}$ & CI \\
\hline \multicolumn{7}{|l|}{ Financial resources } \\
\hline High sports-active & Reference group & & & & & \\
\hline Moderate sports-active & -1.12 & 0.17 & -2.70 to 0.48 & -1.29 & 0.11 & -2.87 to 0.29 \\
\hline Low sports-active & -1.48 & 0.08 & -3.15 to 0.18 & -1.28 & 0.14 & -2.96 to 0.41 \\
\hline Non-members & -3.36 & 0.002 & -5.51 to 1.21 & -3.19 & 0.004 & -5.36 to -0.29 \\
\hline
\end{tabular}

Significant p's are in bold

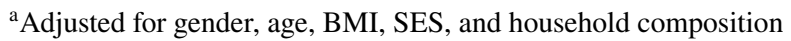

${ }^{\mathrm{b}}$ Unstandardized regression coefficient

social skills children learned at the sports club to their nearby social environment of parents and friends [61, 62].

\section{Performing individual versus team sports}

The only longitudinal association observed in the present study, performing individual sports being longitudinally associated with better 'moods and emotion' compared to performing team sports, is contrary to the conclusion by Vella et al. [21], who found better emotions for children performing team sports. In line with their study, there are many indications that children participating in team sports benefit more from the positive social support, development of social skills and positive peer relationships than children participating in individual sports $[36,51,63]$. However, it may be argued that children performing team sports experience a greater intrinsic pressure [64], a greater pressure from coaches, peers or family $[65,66]$ and more negative team dynamics [67]. This all can lead to a loss of pleasure due to a high sense of 'them and us' [68], and to a loss of autonomy and thus to an increase of boredom or stress [69].

Unlike Vella et al. [21], we did not find a substantial number of longitudinal associations between performing individual versus team sports and better HRQoL. The very small number of significant associations observed in our study may partly be due to the potentially negative aspects of team sports. However, also the fact that children performing individual and children performing team sports experience largely the same group dynamics and social influence in their sport setting at this age could explain the very small difference where the influence on HRQoL is concerned. Although there are indeed different insights in the literature (e.g. Vella et al. [70]), it can be argued that in both types of sports participation, children train together in groups, and when participating in matches also mostly act as a team and experience both the positive and negative aspects of being part of a group event [71, 72].

\section{Performing indoor versus outdoor sports}

In this study, also a limited number of longitudinal associations between performing indoor versus outdoor sports and better HRQoL were observed. This research finding seems, at first sight, to be at odds with studies reporting beneficial effects of being physically active in a natural environment [73]. However, studies in the field of green exercises focus on more forms of physical activity than just sports activities, such as recreational walking, gardening, running and cycling [74], and relate to other environments than sports fields, such as parks, wooded areas and water bodies $[75,76]$. The subject of these studies, therefore, differs significantly from the subject of our study.

Our research finding that performing indoor versus outdoor sports was only to a limited extent longitudinally associated with better HRQoL is in line with insights that especially for a child's HRQoL it is not as relevant whether sports activities are performed in an indoor or an outdoor setting. Hart [77] argues that children consider the environment in which they play sports, primarily as a social meeting place. The location of this social meeting place is of minor importance for them. Reed et al. [61] found that for children green exercises did not create an additional improvement in enjoyment in comparison with outdoor activities in nongreen urban areas. Adams et al. [62] described that children's natural environmental views were not related to their subjective well-being.

However, on the basis of our research, the irrelevance of the distinction between indoor and outdoor sports has to be nuanced for the psychological domain of HRQoL. We observed a weak significant longitudinal association between performing outdoor sports and better 'self-perception'. This association might be explained by the fact that the sometimes changing weather conditions in the open air (e.g. rain, wind power, and sunshine) give children more opportunities to acquire physical strength and endurance. This might be conducive to their subjective vitality (a positive feeling of 
Table 4 Associations between performing individual versus team sports and HRQOL dimensions

\begin{tabular}{|c|c|c|c|c|c|c|c|c|c|}
\hline & \multicolumn{3}{|l|}{ Crude analyses } & \multicolumn{3}{|c|}{ Adjusted $^{\mathrm{a}}$} & \multicolumn{3}{|c|}{ Adjusted $^{\mathrm{b}}$} \\
\hline & $\mathrm{B}^{\mathrm{c}}$ & $\mathrm{p}$ & CI & $\mathrm{B}^{\mathrm{c}}$ & $\mathrm{p}$ & CI & $\mathrm{B}^{\mathrm{c}}$ & $\mathrm{p}$ & CI \\
\hline \multicolumn{10}{|l|}{ Physical domain } \\
\hline \multicolumn{10}{|l|}{ Physical well-being } \\
\hline Individual sports & Reference group & & & & & & & & \\
\hline Team sports & 0.48 & 0.59 & -1.32 to 2.28 & 0.09 & 0.92 & -1.71 to 1.90 & -0.44 & 0.63 & -2.23 to 1.35 \\
\hline $\begin{array}{l}\text { Individual as well as team } \\
\text { sports }\end{array}$ & 1.09 & 0.34 & -1.16 to 3.34 & 1.29 & 0.26 & -0.94 to 3.53 & -0.53 & 0.66 & -2.88 to 1.83 \\
\hline Non-members & -3.31 & 0.004 & -5.58 to -1.04 & -2.96 & 0.01 & -5.22 to -0.70 & -0.15 & 0.91 & -2.73 to 2.43 \\
\hline \multicolumn{10}{|l|}{ Psychological domain } \\
\hline \multicolumn{10}{|l|}{ Psychological well-being } \\
\hline Individual sports & Reference group & & & & & & & & \\
\hline Team sports & 0.54 & 0.53 & -1.14 to 2.22 & 0.57 & 0.52 & -1.14 to 2.27 & 0.10 & 0.91 & -1.60 to 1.80 \\
\hline $\begin{array}{l}\text { Individual as well as team } \\
\text { sports }\end{array}$ & 0.90 & 0.40 & -1.18 to 2.98 & 1.29 & 0.22 & -0.79 to 3.37 & -0.30 & 0.79 & -2.51 to 1.92 \\
\hline Non-members & -0.16 & 0.88 & -2.28 to 1.96 & 0.03 & 0.98 & -2.10 to 2.15 & 2.36 & 0.06 & -0.07 to 4.78 \\
\hline \multicolumn{10}{|l|}{ Moods and emotions } \\
\hline Individual sports & Reference group & & & & & & & & \\
\hline Team sports & -0.67 & 0.09 & -3.70 to 0.27 & -1.94 & 0.06 & -3.95 to 0.08 & -2.22 & $\mathbf{0 . 0 3}$ & -4.24 to -0.20 \\
\hline $\begin{array}{l}\text { Individual as well as team } \\
\text { sports }\end{array}$ & -0.42 & 0.74 & -2.87 to 2.03 & -0.06 & 0.96 & -2.50 to 2.38 & -1.15 & 0.39 & -3.76 to 1.45 \\
\hline Non-members & -1.72 & 0.60 & -3.15 to 1.81 & -0.65 & 0.61 & -3.11 to 1.82 & 0.99 & 0.49 & -1.83 to 3.81 \\
\hline \multicolumn{10}{|l|}{ Self-perception } \\
\hline Individual sports & Reference group & & & & & & & & \\
\hline Team sports & -1.01 & 0.28 & -2.82 to 0.82 & -1.60 & 0.08 & -3.39 to 0.19 & -1.77 & 0.05 & -3.56 to 0.03 \\
\hline $\begin{array}{l}\text { Individual as well as team } \\
\text { sports }\end{array}$ & -0.01 & 1.00 & -2.26 to 2.25 & 0.31 & 0.78 & -1.89 to 2.53 & -0.30 & 0.80 & -2.66 to 2.05 \\
\hline Non-members & -1.01 & 0.39 & -3.30 to 1.28 & -0.77 & 0.50 & -3.01 to 1.48 & 0.57 & 0.66 & -2.01 to 3.15 \\
\hline \multicolumn{10}{|l|}{ Social domain } \\
\hline \multicolumn{10}{|l|}{ Autonomy } \\
\hline Individual sports & Reference group & & & & & & & & \\
\hline Team sports & -0.62 & 0.46 & -2.28 to 1.04 & -0.77 & 0.37 & -2.45 to 0.91 & 0.92 & 0.29 & $-2.61-0.77$ \\
\hline $\begin{array}{l}\text { Individual as well as team } \\
\text { sports }\end{array}$ & -0.63 & 0.55 & -2.73 to 1.46 & -0.21 & 0.84 & -2.30 to 1.88 & -0.72 & 0.53 & -2.95 to 1.52 \\
\hline Non-members & -0.91 & 0.40 & -3.04 to 1.22 & -0.82 & 0.45 & -2.94 to 1.31 & -0.02 & 0.99 & -2.48 to 2.44 \\
\hline \multicolumn{10}{|l|}{ Parents and home life } \\
\hline Individual sports & Reference group & & & & & & & & \\
\hline Team sports & -0.93 & 0.26 & -2.53 to 0.71 & -0.97 & 0.25 & -2.61 to 0.67 & -1.33 & 0.11 & -2.97 to 0.30 \\
\hline $\begin{array}{l}\text { Individual as well as team } \\
\text { sports }\end{array}$ & -0.34 & 0.74 & -2.34 to 1.67 & 0.04 & 0.97 & -1.96 to 2.04 & -1.26 & 0.25 & -3.40 to 0.87 \\
\hline Non-members & -1.82 & 0.08 & -3.79 to 0.28 & -1.66 & 0.11 & -3.68 to 0.37 & 0.28 & 0.81 & -2.04 to 2.60 \\
\hline \multicolumn{10}{|l|}{ Social support and peers } \\
\hline Individual sports & Reference group & & & & & & & & \\
\hline Team sports & -0.91 & 0.31 & -2.67 to 0.85 & -0.73 & 0.42 & -2.53 to 1.06 & -1.09 & 0.23 & -2.89 to 0.71 \\
\hline $\begin{array}{l}\text { Individual as well as team } \\
\text { sports }\end{array}$ & 0.17 & 0.88 & -2.06 to 2.39 & 0.56 & 0.62 & -1.67 to 2.78 & -0.71 & 0.56 & -3.08 to 1.67 \\
\hline Non-members & -2.64 & 0.02 & -4.90 to -0.37 & -2.39 & 0.04 & -4.66 to -0.13 & -0.48 & 0.72 & -3.09 to 2.12 \\
\hline \multicolumn{10}{|l|}{ Social acceptance (bullying) } \\
\hline Individual sports & Reference group & & & & & & & & \\
\hline Team sports & -0.41 & 0.70 & -2.36 to 1.53 & -0.46 & 0.65 & -2.44 to 1.53 & -0.67 & 0.51 & -2.57 to 1.36 \\
\hline $\begin{array}{l}\text { Individual as well as team } \\
\text { sports }\end{array}$ & 0.90 & 0.47 & -1.53 to 3.32 & 1.08 & 0.38 & -1.35 to 3.52 & 0.29 & 0.83 & -1.93 to 3.20 \\
\hline
\end{tabular}


Table 4 (continued)

\begin{tabular}{|c|c|c|c|c|c|c|c|c|c|}
\hline & \multicolumn{3}{|l|}{ Crude analyses } & \multicolumn{3}{|c|}{ Adjusted $^{\mathrm{a}}$} & \multicolumn{3}{|c|}{ Adjusted $^{\mathrm{b}}$} \\
\hline & $\mathrm{B}^{\mathrm{c}}$ & $\mathrm{p}$ & $\mathrm{CI}$ & $\mathrm{B}^{\mathrm{c}}$ & $\mathrm{p}$ & $\mathrm{CI}$ & $\mathrm{B}^{\mathrm{c}}$ & $\mathrm{p}$ & $\mathrm{CI}$ \\
\hline Non-members & -1.35 & 0.28 & -3.81 to 1.10 & -1.20 & 0.34 & -3.68 to 1.27 & -0.03 & 0.98 & -3.07 to 2.52 \\
\hline \multicolumn{10}{|l|}{ School environment } \\
\hline Individual sports & Reference group & & & & & & & & \\
\hline Team sports & -1.77 & 0.04 & -3.42 to -0.12 & -1.44 & 0.09 & -3.12 to 0.24 & -1.57 & 0.07 & -3.27 to 0.11 \\
\hline $\begin{array}{l}\text { Individual as well as team } \\
\text { sports }\end{array}$ & 0.00 & 1.00 & -2.07 to 2.07 & 0.22 & 0.84 & -1.86 to 2.30 & -0.31 & 0.78 & -2.55 to 1.91 \\
\hline Non-members & -0.81 & 0.45 & -2.91 to 1.28 & -0.68 & 0.53 & -2.79 to 1.43 & 0.15 & 0.90 & -2.29 to 2.59 \\
\hline \multicolumn{10}{|l|}{ Financial resources } \\
\hline Individual sports & Reference group & & & & & & & & \\
\hline Team sports & -0.97 & 0.25 & 2.64 to 0.70 & -0.94 & 0.28 & -2.64 to 0.76 & -1.16 & 0.18 & -2.87 to 0.55 \\
\hline $\begin{array}{l}\text { Individual as well as team } \\
\text { sports }\end{array}$ & -0.53 & 0.62 & 2.62 to 1.56 & -0.23 & 0.83 & -2.33 to 1.86 & -1.05 & 0.36 & -3.29 to 1.19 \\
\hline Non-members & -2.89 & 0.01 & -5.02 to -0.77 & -2.67 & 0.01 & -4.80 to -0.54 & -1.43 & 0.25 & -3.88 to 1.02 \\
\hline
\end{tabular}

Significant p's are in bold

adjusted for gender, age, BMI, SES and household composition

${ }^{\mathrm{b}}$ Adjusted for gender, age, BMI, SES, household composition and frequency

${ }^{\mathrm{c}}$ Unstandardized regression coefficient

aliveness and energy), which in turn may enhance their selfperception [58].

\section{Strengths and limitation}

This is one of the few studies examining longitudinal associations between various characteristics of sports participation and HRQoL in children aged 10-12 years. Until now, only Sánchez-López et al. [19], Tsiros et al. [20] and Vella et al. [21] investigated such associations focusing on children in a slightly younger age group.

Moreover, this is the first study investigating longitudinal associations between characteristics of sports participation and HRQoL in children which used a self-reported measure of HRQoL instead of parent reports. In a healthy population, as is the case in our sample, self-report gives in this age group a better indication of the child's HRQoL than parent report [78, 79].

While this study presents relevant findings concerning HRQOL in children, there are also some limitations. Although the time spent in sports participation also seems to be relevant for HRQoL [80], the duration of sports participation was not taken into account in our analyses. Based on self-reported information from the children, rather than objectively measured data about physical activity, we were not able to determine the time spent on sports participation in a valid way.

Although the measure instruments comply with the usual requirements of validity and reliability, a wellknown limitation of a longitudinal observational design as applied in our study concerns the impossibility to establish possible causal relationships, which is a limitation that in general applies to all non-experimental studies. Only statistical associations could be ascertained.

Furthermore, the risk of possible bias due to the applied sampling strategy did not materialize. The group of children included in the study was comparable with the general Dutch population of primary school children aged 10-12 important characteristics such as BMI, SES and membership of a sports club for children.

The group of children in the follow-up differed to a small extent from the dropouts with respect to frequency of sports participation and the HRQoL dimension 'physical wellbeing'. The frequency of sports participation of the dropouts was significant higher and their HRQoL on the dimension 'physical well-being' was significantly lower. These differences may have led to a slight underestimation of some longitudinal associations for frequency of sports participation and a slight overestimation for the HRQoL dimension physical well-being.

Finally, a multiple testing problem could arise because many statistical analyses have been performed. In order to cope with this, we have not focused so much on separate, significant associations in our conclusions, but mainly focused our attention to the overall picture per HRQoL domain. 
Table 5 Associations between performing indoor versus outdoor sports and HRQOL dimensions

\begin{tabular}{|c|c|c|c|c|c|c|c|c|c|}
\hline & \multicolumn{3}{|l|}{ Crude analyses } & \multicolumn{3}{|c|}{ Adjusted analyses $^{\mathrm{a}}$} & \multicolumn{3}{|c|}{ Adjusted analyses ${ }^{b}$} \\
\hline & $\mathrm{B}^{\mathrm{c}}$ & $\mathrm{p}$ & CI & $\mathrm{B}^{\mathrm{c}}$ & $\mathrm{p}$ & $\mathrm{CI}$ & $\mathrm{B}^{\mathrm{c}}$ & $\mathrm{p}$ & $\mathrm{CI}$ \\
\hline \multicolumn{10}{|l|}{ Physical domain } \\
\hline \multicolumn{10}{|l|}{ Physical well-being } \\
\hline Indoor sports & Reference group & & & & & & & & \\
\hline Outdoor sports & 3.26 & $<0.001$ & 1.56 to 4.95 & 2.54 & 0.01 & 0.77 to 4.31 & 1.75 & 0.05 & -0.03 to 3.54 \\
\hline Indoor as well as outdoor sports & 2.67 & $\mathbf{0 . 0 3}$ & 0.24 to 5.09 & 2.86 & 0.02 & 0.45 to 5.27 & 1.08 & 0.41 & -1.48 to 3.64 \\
\hline Non-members & -1.83 & 0.10 & -4.01 to 0.34 & -1.69 & 0.13 & -3.86 to 0.48 & 0.65 & 0.60 & -1.82 to 3.13 \\
\hline \multicolumn{10}{|l|}{ Psychological domain } \\
\hline \multicolumn{10}{|l|}{ Psychological well-being } \\
\hline Indoor sports & Reference group & & & & & & & & \\
\hline Outdoor sports & 2.04 & 0.01 & 0.45 to 3.62 & 1.80 & 0.03 & 0.13 to 3.47 & 1.01 & 0.24 & -0.69 to 2.71 \\
\hline Indoor as well as outdoor sports & 0.95 & 0.41 & -1.33 to 3.23 & 1.17 & 0.32 & -1.11 to 3.44 & -0.53 & 0.67 & -2.95 to 1.89 \\
\hline Non-members & 0.54 & 0.60 & -1.50 to 2.57 & 0.50 & 0.63 & -1.54 to 2.54 & 2.68 & 0.02 & 0.36 to 5.00 \\
\hline \multicolumn{10}{|l|}{ Moods and emotions } \\
\hline Indoor sports & Reference group & & & & & & & & \\
\hline Outdoor sports & 2.63 & 0.01 & 0.75 to 4.53 & 2.21 & $\mathbf{0 . 0 3}$ & $0.22-4.20$ & 1.79 & 0.09 & -0.25 to 3.83 \\
\hline Indoor as well as outdoor sports & 2.11 & 0.12 & -0.58 to 4.79 & 2.33 & 0.09 & -0.34 to 5.00 & 1.44 & 0.32 & -1.42 to 4.31 \\
\hline Non-members & 1.83 & 0.13 & -0.55 to 4.22 & 1.63 & 0.18 & -0.75 to 4.01 & 2.76 & 0.05 & 0.04 to 5.47 \\
\hline \multicolumn{10}{|l|}{ Self-perception } \\
\hline Indoor sports & Reference group & & & & & & & & \\
\hline Outdoor sports & 3.13 & $<0.001$ & 1.42 to 4.84 & 1.97 & $\mathbf{0 . 0 3}$ & 0.22 to 3.73 & 1.82 & 0.05 & 0.01 to 3.62 \\
\hline Indoor as well as outdoor sports & 3.37 & 0.01 & 0.92 to 5.82 & 3.80 & 0.002 & 1.40 to 6.19 & 3.26 & 0.01 & 0.88 to 6.03 \\
\hline Non-members & 1.45 & 0.19 & -0.73 to 3.64 & 1.39 & 0.20 & -0.76 to 3.55 & 1.84 & 0.15 & -0.64 to 4.32 \\
\hline \multicolumn{10}{|l|}{ Social domain } \\
\hline \multicolumn{10}{|l|}{ Autonomy } \\
\hline Indoor sports & Reference group & & & & & & & & \\
\hline Outdoor sports & 0.54 & $\mathbf{0 . 0 3}$ & 0.20 to 3.34 & 1.33 & 0.11 & -0.32 to 2.98 & 1.19 & 0.17 & -0.50 to 2.89 \\
\hline Indoor as well as outdoor sports & 1.03 & 0.37 & -1.24 to 3.30 & 1.33 & 0.25 & -0.93 to 3.59 & 1.01 & 0.41 & -1.42 to 3.45 \\
\hline Non-members & 1.77 & 0.60 & -1.50 to 2.59 & 0.41 & 0.69 & -1.63 to 2.46 & 0.83 & 0.49 & -1.53 to 3.20 \\
\hline \multicolumn{10}{|l|}{ Parents and home life } \\
\hline Indoor sports & Reference group & & & & & & & & \\
\hline Outdoor sports & 1.97 & 0.01 & 0.42 to 3.51 & 0.69 & 0.05 & 0.03 to 3.28 & 1.19 & 0.16 & -0.48 to 2.85 \\
\hline Indoor as well as outdoor sports & 2.17 & 0.05 & -0.02 to 4.36 & 2.37 & $\mathbf{0 . 0 3}$ & 0.19 to 4.55 & 1.33 & 0.27 & -1.01 to 3.66 \\
\hline Non-members & -0.01 & 0.99 & -1.97 to 1.95 & -0.05 & 0.96 & -2.00 to 1.91 & 1.29 & 0.26 & -0.94 to 3.52 \\
\hline \multicolumn{10}{|l|}{ Social support and peers } \\
\hline Indoor sports & Reference group & & & & & & & & \\
\hline Outdoor sports & 1.59 & 0.06 & -0.07 to 3.26 & 1.64 & 0.07 & -0.12 to 3.40 & 1.04 & 0.26 & -0.77 to 2.84 \\
\hline Indoor as well as outdoor sports & 0.53 & 0.67 & -1.89 to 2.95 & 0.70 & 0.57 & -1.71 to 3.11 & -0.65 & 0.62 & -3.23 to 1.94 \\
\hline Non-members & -1.31 & 0.24 & -3.49 to 0.88 & -1.26 & 0.26 & -3.44 to 0.91 & 0.53 & 0.68 & $-1.97-3.03$ \\
\hline \multicolumn{10}{|l|}{ Social acceptance (bullying) } \\
\hline Indoor sports & Reference group & & & & & & & & \\
\hline Outdoor sports & 2.01 & 0.03 & 0.17 to 3.87 & 1.80 & 0.07 & -0.15 to 3.75 & 1.51 & 0.14 & -0.50 to 3.52 \\
\hline Indoor as well as outdoor sports & 2.62 & 0.05 & -0.03 to 5.26 & 2.70 & 0.05 & 0.05 to 5.35 & 2.07 & 0.15 & -0.78 to 4.92 \\
\hline Non-members & 0.04 & 0.97 & -2.32 to 2.40 & 0.03 & 0.98 & -2.35 to 2.41 & 0.83 & 0.55 & -1.90 to 3.56 \\
\hline \multicolumn{10}{|l|}{ School environment } \\
\hline Indoor sports & Reference group & & & & & & & & \\
\hline Outdoor sports & -1.14 & 0.16 & -2.70 to 0.44 & -0.92 & 0.28 & -2.57 to 0.73 & -1.17 & 0.18 & -2.87 to 0.53 \\
\hline Indoor as well as outdoor sports & 1.40 & 0.22 & -0.85 to 3.65 & 1.49 & 0.20 & -0.77 to 3.75 & 0.93 & 0.45 & -1.50 to 3.35 \\
\hline Non-members & -0.28 & 0.79 & -2.30 to 1.74 & -0.20 & 0.84 & -2.24 to 1.83 & 0.53 & 0.66 & -1.81 to 2.88 \\
\hline
\end{tabular}


Table 5 (continued)

\begin{tabular}{|c|c|c|c|c|c|c|c|c|c|}
\hline & \multicolumn{3}{|c|}{ Crude analyses } & \multicolumn{3}{|c|}{ Adjusted analyses $^{\mathrm{a}}$} & \multicolumn{3}{|c|}{ Adjusted analyses ${ }^{\mathrm{b}}$} \\
\hline & $\mathrm{B}^{\mathrm{c}}$ & $\mathrm{p}$ & $\mathrm{CI}$ & $\mathrm{B}^{\mathrm{c}}$ & $\mathrm{p}$ & $\mathrm{CI}$ & $\mathrm{B}^{\mathrm{c}}$ & $\mathrm{p}$ & CI \\
\hline \multicolumn{10}{|l|}{ Financial resources } \\
\hline Indoor sports & Referen & & & & & & & & \\
\hline Outdoor sports & 2.63 & 0.001 & 1.05 to 4.21 & 2.56 & 0.003 & 0.90 to 4.21 & 2.36 & 0.01 & 0.65 to 4.07 \\
\hline Indoor as well as outdoor sports & 2.26 & 0.05 & -0.01 to 5.53 & 2.54 & $\mathbf{0 . 0 3}$ & 0.28 to 4.81 & 2.11 & 0.09 & -0.33 to 4.54 \\
\hline Non-members & -0.73 & 0.48 & -2.76 to 1.31 & -0.68 & 0.51 & -2.71 to 1.36 & -0.12 & 0.92 & -2.46 to 2.22 \\
\hline
\end{tabular}

Significant p's are in bold

${ }^{a}$ Adjusted for gender, age, BMI, SES and household composition

${ }^{\mathrm{b}}$ Adjusted for gender, age, BMI, SES, household composition and frequency of sports participation

${ }^{\mathrm{c}}$ Unstandardized regression coefficient

\section{Future research}

In future research, other characteristics of sports participation like duration and intensity could also be taken into account. Furthermore, in addition to self-report data, information from accelerometers could be used to increase validity. Finally, future research preferably takes place in the form of an intervention in order to find out whether the statistical associations observed in our study are of a causal nature.

\section{Conclusion}

Better HRQoL is to a considerable extent longitudinally associated with higher frequency of sports participation and only to a limited extent longitudinally associated with performing individual sports and performing outdoor sports. Frequency of sports participation seems to be much more relevant for a child's HRQoL than the kind of sport(s) in which the child participates. Therefore, the choice for a sport that the child can and likes to do with a relatively high frequency is presumably more important than the choice for a certain type of sport.

Acknowledgements We gratefully thank the primary school children involved in the study, their parents or guardians, and the primary schools that facilitated data gathering.

Author contributions The study was designed by JM, RB and JT. Analysis was performed by JM, JvB and JT. The first draft of the paper was written by JM, and all authors provided critical input and reviewed drafts of the manuscript. JM finalized the manuscript which was subsequently approved by all authors.

\section{Compliance with ethical standards}

Conflict of interest The authors declare that they have no conflict of interest.
Ethical approval All procedures performed in this study involving human participants were in accordance with the ethical standards of the institutional and/or national research committee and with the 1964 Helsinki Declaration and its later amendments or comparable ethical standards. Ethical approval was obtained from the Medical Ethics Committee of VU University Amsterdam (12/151).

Informed consent Informed consent was obtained from all individual participants included in the study.

Open Access This article is distributed under the terms of the Creative Commons Attribution 4.0 International License (http://creativeco mmons.org/licenses/by/4.0/), which permits unrestricted use, distribution, and reproduction in any medium, provided you give appropriate credit to the original author(s) and the source, provide a link to the Creative Commons license, and indicate if changes were made.

\section{References}

1. Michel, G., Bisegger, C., Fuhr, D. C., \& Abel, T. (2009). Age and gender differences in health-related quality of life of children and adolescents in Europe: A multilevel analysis. Quality of Life Research, 18(9), 1147-1157. https://doi.org/10.1007/s1113 6-009-9538-3.

2. Petersen-Ewert, C., Erhart, M., \& Ravens-Sieberer, U. (2011). Assessing health-related quality of life in European children and adolescents. Neuroscience and Biobehavioral Reviews, 35(8), 1752-1756. https://doi.org/10.1016/j.neubiorev.2011.02.012.

3. The KIDSCREEN-group Europe. (2006). The kidscreen questionnaires - quality of life questionnaires for children and adolescent—handbook. Lengerich: Pabst Science Publishers.

4. Wilson, I. B., \& Cleary, P. D. (1995). Linking clinical variables with health-related quality of life: A conceptual model of patient outcomes. JAMA, 273(1), 59-65.

5. Eime, R. M., Young, J. A., Harvey, J. T., Charity, M. J., \& Payne, W. R. (2013). A systematic review of the psychological and social benefits of participation in sport for adults: Informing development of a conceptual model of health through sport. International Journal of Behavioral Nutrition and Physical Activity, 10(1), 135-148. https://doi.org/10.1186/1479-5868-10-135.

6. Eime, R. M., Young, J. A., Harvey, J. T., Charity, M. J., \& Payne, W. R. (2013). A systematic review of the psychological and social 
benefits of participation in sport for children and adolescents: Informing development of a conceptual model of health through sport. International Journal of Behavioral Nutrition and Physical Activity, 10(1), 98-119. https://doi.org/10.1186/1479-5868-10-98.

7. Wu, X. Y., Han, L. H., Zhang, J. H., Luo, S., Hu, J. W., \& Sun, K. (2017). The influence of physical activity, sedentary behavior on health-related quality of life among the general population of children and adolescents: A systematic review. PLOS ONE, 12(11), e0187668. https://doi.org/10.1371/journal.pone.0187668.

8. Marker, A. M., Steele, R. G., \& Noser, A. E. (2018). Physical activity and health-related quality of life in children and adolescents: A systematic review and meta-analysis. Health Psychology, $37(10), 893$.

9. Jalali-Farahani, S., Amiri, P., \& Chin, Y. S. (2016). Are physical activity, sedentary behaviors and sleep duration associated with body mass index-for-age and health-related quality of life among high school boys and girls? Health and Quality of Life Outcomes, 14(1), 30

10. Linver, M. R., Roth, J. L., \& Brooks-Gunn, J. (2009). Patterns of adolescents' participation in organized activities: Are sports best when combined with other activities? Developmental Psychology, 45(2), 354-367. https://doi.org/10.1037/a0014133.

11. Snyder, A. R., Martinez, J. C., Bay, R. C., Parsons, J. T., Sauers, E. L., \& Valovich McLeod, T. C. (2010). Health-related quality of life differs between adolescent athletes and adolescent nonathletes. Journal of Sport Rehabilitation, 19(3), 237-248. https://doi. org/10.1123/jsr.19.3.237.

12. Spengler, S., \& Woll, A. (2013). The more physically active, the healthier? The relationship between physical activity and healthrelated quality of life in adolescents: the MoMo study. Journal of Physical Activity and Health, 10(5), 708-715. https://doi. org/10.1123/jpah.10.5.708.

13. Valois, R. F., Zullig, K. J., Huebner, E. S., \& Drane, J. W. (2004). Physical activity behaviors and perceived life satisfaction among public high school adolescents. Journal of School Health, 74(2), $59-65$.

14. Michaud, P.-A., Jeannin, A., \& Suris, J.-C. (2006). Correlates of extracurricular sport participation among Swiss adolescents. European Journal of Pediatrics, 165(8), 546.

15. Steptoe, A., \& Butler, N. (1996). Sports participation and emotional wellbeing in adolescents. The Lancet, 347(9018), 1789-1792.

16. Ferron, C., Narring, F., Cauderay, M., \& Michaud, P.-A. (1999). Sport activity in adolescence: associations with health perceptions and experimental behaviours. Health Education Research, 14(2), 225-233.

17. Donaldson, S. J., \& Ronan, K. R. (2006). The effects of sports participation on young adolescents' emotional well-being. Adolescence, 41(162), 369-389.

18. Findlay, L. C., \& Coplan, R. J. (2008). Come out and play: Shyness in childhood and the benefits of organized sports participation. Canadian Journal of Behavioural Science/Revue canadienne des sciences du comportement, 40(3), 153-161. https://doi.org/10.1037/0008-400X.40.3.153.

19. Sánchez-López, M., Salcedo-Aguilar, F., Solera-Martínez, M., Moya-Martínez, P., Notario-Pacheco, B., \& Martínez-Vizcaíno, V. (2009). Physical activity and quality of life in schoolchildren aged 11-13 years of Cuenca, Spain. Scandinavian Journal of Medicine and Science in Sports, 19(6), 879-884. https://doi.org /10.1111/j.1600-0838.2008.00839.x.

20. Tsiros, M. D., Samaras, M. G., Coates, A. M., \& Olds, T. (2017). Use-of-time and health-related quality of life in 10-to 13-year-old children: Not all screen time or physical activity minutes are the same. Quality of Life Research, 26(11), 31193129. https://doi.org/10.1007/s11136-017-1639-9.
21. Vella, S. A., Cliff, D. P., Magee, C. A., \& Okely, A. D. (2014). Sports participation and parent-reported health-related quality of life in children: Longitudinal associations. Journal of Pediatrics, 164(6), 1469-1474. https://doi.org/10.1016/j.jpeds .2014.01.071

22. Coalter, F. (2015). Sport-for-change: Some thoughts from a sceptic. Social Inclusion, 3(3), 19-23. https://doi.org/10.17645 /si.v3i3.222

23. Ministry of Public Health. (2018). Sociaaleconomische status [Social economic status]. Retrieved from https://www.volksgezon dheidenzorg.info/onderwerp/sociaaleconomische-status/regio naal-internationaal/regionaal\#node-kinderen-armoede-gemeente. Accessed April 1, 2018.

24. National Dutch Central Organization of Statistics. (2017). StatLine. Retrieved from https://opendata.cbs.nl/statline/\#/CBS/nl/ dataset/81565NED/table?ts=1522696339228. Accessed March 3, 2018.

25. Kenniscentrum Sport. (2017). Alles over sport [All about sports]. https://www.allesoversport.nl/artikel/mensen-met-een-lage-socia al-economische-status-wat-drijft-en-belemmert-hen-bij-sport-enbewegen/. Accessed June 14, 2018.

26. Eiser, C., \& Kopel, S. (2013). Children's perception of health and illness. In K. J. Petrie \& J. A. Weinman (Eds.), Perceptions of health and illness; Current research and applications (pp. 47-76). London/New York: Routledge.

27. Eccles, J. S. (1999). The development of children ages 6 to 14 . The Future of Children, 9(2), 30-44.

28. Patton, G. C., \& Viner, R. (2007). Pubertal transitions in health. Lancet, 369(9567), 1130-1139. https://doi.org/10.1016/S0140 -6736(07)60366-3.

29. Ravens-Sieberer, U., Gosch, A., Rajmil, L., Erhart, M., Bruil, J., Duer, W., et al. (2005). KIDSCREEN-52 quality-of-life measure for children and adolescents. Expert Review of Pharmacoeconomics \& Outcomes Research, 5(3), 353-364. https://doi. org/10.1586/14737167.5.3.353.

30. WHOQOL Group. (1993). Study protocol for the World Health Organization project to develop a quality of life assessment instrument (WHOQOL). Quality of Life Research, 2(2), 153-159. https ://doi.org/10.1007/BF00435734.

31. Bullinger, M., Alonso, J., Apolone, G., Leplège, A., Sullivan, M., Wood-Dauphinee, S., et al. (1998). Translating health status questionnaires and evaluating their quality: The IQOLA project approach. Journal of Clinical Epidemiology, 51(11), 913-923. https://doi.org/10.1016/S0895-4356(98)00082-1.

32. Ravens-Sieberer, U., Herdman, M., Devine, J., Otto, C., Bullinger, M., Rose, M., et al. (2014). The European KIDSCREEN approach to measure quality of life and well-being in children: Development, current application, and future advances. Quality of Life Research, 23(3), 791-801. https://doi.org/10.1007/s1113 6-013-0428-3.

33. Collard, D., \& Pulles, I. (2015). Factsheet 2015/16 Sportdeelname [Factsheet 2015/16 Sports participation]. Utrecht: Mulier Instituut.

34. Ooijendijk, W., Wendel-Vos, W., \& De Vries, S. (2007). Consensus Vragenlijsten Sport en Bewegen (KvL//B\&G 2007.089) [Consensus Questionnaires Sports and Movement $(K v L / / B \& G$ 2007.089)]. Leiden: TNO Kwaliteit van Leven.

35. Moeijes, J., Van Busschbach, J. T., Fortuin, B., Bosscher, R. J., \& Twisk, J. W. (2017). Sports participation and psychosocial health in elementary school children. Health Behavior and Policy Review, 4(6), 582-592. https://doi.org/10.14485/ HBPR.4.6.8.

36. Breslin, G., Gossrau-Breen, D., McCay, N., Gilmore, G., MacDonald, L., \& Hanna, D. (2012). Physical activity, gender, weight status, and wellbeing in 9-to 11-year-old children: A cross-sectional 
survey. Journal of Physical Activity and Health, 9(3), 394-401. https://doi.org/10.1123/jpah.9.3.394.

37. Vella, S. A., Magee, C. A., \& Cliff, D. P. (2015). Trajectories and predictors of health-related quality of life during childhood. Journal of Pediatrics, 167(2), 422-427. https://doi.org/10.1016/j. jpeds.2015.04.079.

38. Chen, X., Sekine, M., Hamanishi, S., Yamagami, T., \& Kagamimori, S. (2005). Associations of lifestyle factors with quality of life (QOL) in Japanese children: A 3-year follow-up of the Toyama Birth Cohort Study. Child: Care, Health and Development, 31(4), 433-439. https://doi.org/10.1111/j.1365-2214.2005.00529 .x.

39. Cole, T. J., Bellizzi, M. C., Flegal, K. M., \& Dietz, W. H. (2000). Establishing a standard definition for child overweight and obesity worldwide: International survey. British Medical Journal, 320, 1240-1245. https://doi.org/10.1136/bmj.320.7244.1240.

40. Lee, D., \& McLanahan, S. (2015). Family structure transitions and child development: Instability, selection, and population heterogeneity. American Sociological Review, 80(4), 738-763. https ://doi.org/10.1177/0003122415592129.

41. Knol, F., Boelhouwer, J., \& Ross, J. A. (2010). Statusontwikkeling van wijken in Nederland 1998-2010 [Status development of neighborhoods in the Netherland 1998-2010]. Retrieved from http://www.scp.nl/Publicaties/Alle_publicaties/Publicaties_2012/ Statusontwikkeling_van_wijken_in_Nederland_1998_2010. Accessed January 15, 2013.

42. Eime, R. M., Harvey, J. T., Brown, W. J., \& Payne, W. R. (2010). Does sports club participation contribute to health-related quality of life? Medicine and Science in Sports and Exercise, 42(5), 1022-1028. https://doi.org/10.1249/MSS.0b013e3181c3adaa.

43. Downward, P., \& Rasciute, S. (2011). Does sport make you happy? An analysis of the well-being derived from sports participation. International Review of Applied Economics, 25(3), 331-348. https://doi.org/10.1080/02692171.2010.511168

44. Van Hout, R., Young, M. E., Bassett, S., \& Hooft, T. (2013). Participation in sport and the perceptions of quality of life of high school learners in the Theewaterskloof Municipality, South Africa. African Journal for Physical, Health Education, Recreation and Dance, 19(3), 612-622.

45. Gopinath, B., Hardy, L. L., Baur, L. A., Burlutsky, G., \& Mitchell, P. (2012). Physical activity and sedentary behaviors and healthrelated quality of life in adolescents. Pediatrics, 130, e167-e174. https://doi.org/10.1542/peds.2011-3637.

46. Morales, P. F., Sánchez-López, M., Moya-Martínez, P., GarcíaPrieto, J. C., Martínez-Andrés, M., García, N. L., et al. (2013). Health-related quality of life, obesity, and fitness in schoolchildren: the Cuenca study. Quality of Life Research, 22(7), 15151523. https://doi.org/10.1007/s11136-012-0282-8.

47. Gray, C., Gibbons, R., Larouche, R., Sandseter, E. B. H., Bienenstock, A., Brussoni, M., et al. (2015). What is the relationship between outdoor time and physical activity, sedentary behaviour, and physical fitness in children? A systematic review. International Journal of Environmental Research and Public Health, 12(6), 6455-6474. https://doi.org/10.3390/ijerph120606455.

48. Gu, X., Chang, M., \& Solmon, M. A. (2016). Physical activity, physical fitness, and health-related quality of life in school-aged children. Journal of Teaching in Physical Education, 35(2), 117126. https://doi.org/10.1123/jtpe.2015-0110.

49. Borras, P. A., Vidal, J., Ponseti, X., Cantallops, J., \& Palou, P. (2011). Predictors of quality of life in children. Journal of Human Sport and Exercise, 6(4), 649-656. https://doi.org/10.4100/ jhse.2011.64.08

50. Howie, L. D., Lukacs, S. L., Pastor, P. N., Reuben, C. A., \& Mendola, P. (2010). Participation in activities outside of school hours in relation to problem behavior and social skills in middle childhood. Journal of School Health, 80(3), 119-125. https://doi. org/10.1111/j.1746-1561.2009.00475.x.

51. Chen, G., Ratcliffe, J., Olds, T., Magarey, A., Jones, M., \& Leslie, E. (2014). BMI, health behaviors, and quality of life in children and adolescents: A school-based study. Pediatrics, 133(4), e868e874. https://doi.org/10.1542/peds.2013-0622.

52. Biddle, S., \& Mutrie, N. (1991). Psychology of physical activity and exercise: A health-related perspective. London: Springer.

53. Bluemke, M., Brand, R., Schweizer, G., \& Kahlert, D. (2010). Exercise might be good for me, but I don't feel good about it: Do automatic associations predict exercise behavior? Journal of Sport and Exercise Psychology, 32(2), 137-153.

54. Rhodes, R. E., \& Kates, A. (2015). Can the affective response to exercise predict future motives and physical activity behavior? A systematic review of published evidence. Annals of Behavioral Medicine, 49(5), 715-731.

55. Ryan, R. M., \& Frederick, C. (1997). On energy, personality, and health: Subjective vitality as a dynamic reflection of well-being. Journal of Personality, 65(3), 529-565. https://doi. org/10.1111/j.1467-6494.1997.tb00326.x.

56. Reed, J., \& Buck, S. (2009). The effect of regular aerobic exercise on positive-activated affect: A meta-analysis. Psychology of Sport and Exercise, 10(6), 581-594. https://doi.org/10.1016/j. psychsport.2009.05.009.

57. Teixeira, P. J., Carraça, E. V., Markland, D., Silva, M. N., \& Ryan, R. M. (2012). Exercise, physical activity, and self-determination theory: A systematic review. International Journal of Behavioral Nutrition and Physical Activity, 9(1), 78. https://doi. org/10.1186/1479-5868-9-78.

58. Babic, M. J., Morgan, P. J., Plotnikoff, R. C., Lonsdale, C., White, R. L., \& Lubans, D. R. (2014). Physical activity and physical selfconcept in youth: Systematic review and meta-analysis. Sports Medicine, 44(11), 1589-1601. https://doi.org/10.1007/s4027 9-014-0229-z.

59. Robinson, L. E., Stodden, D. F., Barnett, L. M., Lopes, V. P., Logan, S. W., Rodrigues, L. P., et al. (2015). Motor competence and its effect on positive developmental trajectories of health. Sports Medicine, 45(9), 1273-1284. https://doi.org/10.1007/s4027 9-015-0351-6.

60. Liu, M., Wu, L., \& Ming, Q. (2015). How does physical activity intervention improve self-esteem and self-concept in children and adolescents? Evidence from a meta-analysis. PLOS ONE, 10(8), e0134804. https://doi.org/10.1371/journal.pone.0134804.

61. Holt, N. L., Tamminen, K. A., Tink, L. N., \& Black, D. E. (2009). An interpretive analysis of life skills associated with sport participation. Qualitative Research in Sport and Exercise, 1(2), 160-175. https://doi.org/10.1080/19398440902909017.

62. Pierce, S., Gould, D., \& Camiré, M. (2017). Definition and model of life skills transfer. International Review of Sport and Exercise Psychology, 10(1), 186-211. https://doi.org/10.1080/17509 84X.2016.1199727.

63. Gould, D., \& Carson, S. (2008). Life skills development through sport: Current status and future directions. International Review of Sport and Exercise Psychology, 1(1), 58-78. https://doi. org/10.1080/17509840701834573.

64. Hertting, K., \& Kostenius, C. (2012). Organized leisure activities and well-being: Children getting it just right! Larnet: Cyber. Journal of Applied Leisure and Recreational Research, 15(2), 13-28.

65. Chan, D. K., Lonsdale, C., \& Fung, H. H. (2012). Influences of coaches, parents, and peers on the motivational patterns of child and adolescent athletes. Scandinavian Journal of Medicine and Science in Sports, 22(4), 558-568. https://doi.org/10.111 1/j.1600-0838.2010.01277.x.

66. Evans, M. B., Allan, V., Vierimaa, M., \& Côté, J. (2016). Sport parent roles in fostering positive youth development. In S. B. Dagkas \& B. Lisette (Eds.), Families, young people, physical activity 
and health: Critical perspectives (pp. 228-240). London/New York: Routledge.

67. Gould, D., \& Carson, S. (2010). The relationship between perceived coaching behaviors and developmental benefits of high school sports participation. Hellenic Journal of Psychology, 7(1), 298-314.

68. Crane, J., \& Temple, V. (2015). A systematic review of dropout from organized sport among children and youth. European Physical Education Review, 21(1), 114-131.

69. Amado, D., Sánchez-Oliva, D., González-Ponce, I., PulidoGonzález, J. J., \& Sánchez-Miguel, P. A. (2015). Incidence of parental support and pressure on their children's motivational processes towards sport practice regarding gender. PLOS ONE, 10(6), $\mathrm{e} 0128015$.

70. Vella, S. A., Oades, L. G., \& Crowe, T. P. (2013). The relationship between coach leadership, the coach-athlete relationship, team success, and the positive developmental experiences of adolescent soccer players. Physical Education and Sport Pedagogy, 18(5), 549-561.

71. Evans, M. B., Eys, M. A., \& Bruner, M. W. (2012). Seeing the "we" in "me" sports: The need to consider individual sport team environments. Canadian Psychology/Psychologie Canadienne, 53(4), 301. https://doi.org/10.1037/a0030202.

72. Donkers, J. L., Martin, L. J., \& Evans, M. B. (2016). Psychological collectivism in youth athletes on individual sport teams. International Journal of Sport and Exercise Psychology, 16(3), 285-299. https://doi.org/10.1080/1612197X.2016.1218529.

73. McCracken, D. S., Allen, D. A., \& Gow, A. J. (2016). Associations between urban greenspace and health-related quality of life in children. Preventive Medicine Reports, 3, 211-221. https://doi. org/10.1016/j.pmedr.2016.01.013.

74. Thompson Coon, J., Boddy, K., Stein, K., Whear, R., Barton, J., \& Depledge, M. H. (2011). Does participating in physical activity in outdoor natural environments have a greater effect on physical and mental wellbeing than physical activity indoors? A systematic review. International Journal of Environmental Science and Technology, 45(5), 1761-1772. https://doi.org/10.1021/es102947t.

75. Tillmann, S., Tobin, D., Avison, W., \& Gilliland, J. (2018). Mental health benefits of interactions with nature in children and teenagers: A systematic review. Journal of Epidemiology and Community Health. https://doi.org/10.1136/jech-2018-210436.

76. Huynh, Q., Craig, W., Janssen, I., \& Pickett, W. (2013). Exposure to public natural space as a protective factor for emotional well-being among young people in Canada. [journal article]. BMC Public Health, 13(1), 407.

77. Hart, R. (1979). Children's experience of place. New York: Irvington.

78. Rajmil, L., López, A. R., López-Aguilà, S., \& Alonso, J. (2013). Parent-child agreement on health-related quality of life (HRQOL): A longitudinal study. Health and Quality of Life Outcomes, 11(1), 101. https://doi.org/10.1186/1477-7525-11-101.

79. Helseth, S., Haraldstad, K., \& Christophersen, K.-A. (2015). A cross-sectional study of health related quality of life and body mass index in a Norwegian school sample (8-18 years): A comparison of child and parent perspectives. Health and Quality of Life Outcomes, 13(1), 47. https://doi.org/10.1186/s1295 5-015-0239-Z.

80. Poitras, V. J., Gray, C. E., Borghese, M. M., Carson, V., Chaput, J.-P., Janssen, I., et al. (2016). Systematic review of the relationships between objectively measured physical activity and health indicators in school-aged children and youth. Applied Physiology, Nutrition, and Metabolism, 41(6), S197-S239. https://doi. org/10.1139/apnm-2015-0663.

Publisher's Note Springer Nature remains neutral with regard to jurisdictional claims in published maps and institutional affiliations.

\section{Affiliations}

\section{Janet Moeijes ${ }^{1,2}$ (1) Jooske T. van Busschbach ${ }^{1,3} \cdot$ Ruud J. Bosscher $^{1} \cdot$ Jos W. R. Twisk $^{2}$}

Jooske T. van Busschbach

jt.van.busschbach@windesheim.nl

Ruud J. Bosscher

rjbosscher@gmail.com

Jos W. R. Twisk

jwr.twisk@vumc.nl

1 Department of Human Movement and Education,

Windesheim University of Applied Sciences, Campus 2-6,

8017 CA Zwolle, The Netherlands
2 Department of Epidemiology and Biostatistics, Amsterdam Public Health Research Institute, Amsterdam UMC, Vrije Universiteit Amsterdam, Van der Boechorststraat 7, 1081 BT Amsterdam, The Netherlands

3 University Center for Psychiatry, University Medical Center Groningen, University of Groningen, P.O. Box 30001, 9700 RB Groningen, The Netherlands 